\title{
Towards a Radically Pragmatic Theory of If-Conditionals
}

\author{
Gunnar Björnsson \\ Linköping University \\ University of Gothenburg \\ gunnar.bjornsson@liu.se
}

\section{Overview}

It is generally agreed that constructions of the form "if P, Q" are capable of conveying a number of different relations between antecedent and consequent, with pragmatics playing a central role in determining these relations. Controversy concerns what the conventional contribution of the if-clause is, how it constrains the pragmatic processes, and what those processes are. In this essay, I begin to argue that the conventional contribution of if-clauses to semantics is exhausted by the fact that these clauses introduce a proposition without presenting it as true so that the consequent can be understood in relation to it. Given our cognitive interests in such non-truth-presentational introductions, conditionals will make salient the wide but nevertheless disciplined variety of contents that we naturally attribute to them; no further substantial constraints of the sorts proposed by standard theories of conditionals are needed to explain the phenomena. If this is correct, it provides prima facie evidence for a radically contextualist account of conditionals according to which conditionals have no truth-evaluable or intuitively complete content absent some contextually provided, sufficiently salient relation between antecedent and consequent.

\section{The challenge: Making sense of great but restricted variation}

As illustrated by the following list, if-conditionals are capable of conveying a wide variety of relations between the antecedent (the content represented by the if-clause), and the consequent (the content represented by the main clause):

(1) If you are really hungry, you will have a hard time concentrating.

(2) If you are really hungry, you didn't eat enough.

(3) If you are really hungry, you should order something else. 
(4) If you are really hungry, Bill still won't offer you any of his food.

(5) If you are really hungry, there are some old sandwiches in the kitchen.

(6) If you are really hungry, please do have a sandwich before we leave!

(7) Did he break anything? And if he did, does he have insurance?

(8) I don't know whether my friend has a student ID, but if she does, is she entitled to a rebate?

(9) If we are only talking about taste, you should order the fried mozzarella sticks. ${ }^{1}$

(10) If you believe Gottfried, everything is fine and dandy.

(11) If you look to your right, the book is on the top shelf.

(12) If you are Lance Armstrong, what do you do next to improve?

(13) If you know what a dundertabbe is, that is exactly what she did.

(14) If I may toot my own horn, our group made the transition months ago.

Sentence (1) through (3) would be used to communicate that the case at hand is such that being really hungry causes having a hard time concentrating, indicates that one did not eat enough, and provides a sufficient normative reason to order something else, respectively, whereas (4) would be used to communicate that the case in question isn't such that being really hungry undermines the other person's disposition not to offer food. Sentence (5) states that there are some old sandwiches in the kitchen, and indicates a condition - that the addressee is really hungry - under which that stated fact would be relevant. Sentences (6) and (7) would be used to make a conditional command and a conditional question, respectively, where the if-clause states a condition under which the main clause commands action or requests an answer, while (8) would be used to categorically ask a question about a conditional content. The antecedent of (9) would be used to restrict the practical modal expressed by the consequent, whereas the antecedents of (10), (11) and (12) would be used to indicate the perspective from which the consequent should be understood, and those of (13) and (14) to express that the speaker is not taking for granted that the hearer understands the expression (anaphorically) employed in the assertion made by the main clause, or that it is appropriate to bring up one's own achievements as done by uttering the main clause.

Consider three interesting features of this variety of relations. The first is that it seems radically diverse. Some of these relations are, intuitively, relations of conditionality: the main

\footnotetext{
${ }^{1}$ From Jamie Dreier, in conversation.
} 
clause is conditional on the if-clause in some way: witness (1), (2), (3), (6) and (7), (8). Others are not: the truth of the main clause is independent of the if-clause, and the speech act performed is performed regardless: witness (5) and (11) through (14). ${ }^{2}$ Likewise, whereas some relations seem to be between the antecedent and a speech act made by the main clause - most clearly (6), (7), (13) and (14) — others seem to create complex contents that are themselves objects of speech acts - most clearly (1), (2), (4) and (8), and perhaps also (9) and $(10)^{3}$

The second interesting feature is that, although radical, this diversity is also strongly restricted. Though interpretation of the relation between clauses is flexible, it seems considerably less flexible than that of demonstratives like "this" or "that". We clearly do not ascribe whatever relation would make the conditional true, or whatever relation happens to be most salient in the context where the conditional is uttered: "If $\mathrm{P}, \mathrm{Q}$ " never expresses that $\mathrm{P}$ would make $\mathrm{Q}$ less probable, or that $\mathrm{P}$ is more desirable than $\mathrm{Q}$. One way in which such restrictions on contents are revealed is in restrictions on acceptability or truth of conditionals, and philosophers have attempted to characterize such restrictions in general terms. Among constraints that concern the truth-conditions of conditionals, the best known and most widely accepted is that the truth-conditions of the corresponding material implication should obtain: "If $\mathrm{P}, \mathrm{Q}$ " is only true if $\neg(\mathrm{P} \wedge \neg \mathrm{Q}){ }^{4}$

2 (9) and (10) might also belong to this category. See section 11.

${ }^{3}$ Some think that (5) is a speech act conditional; I suspect that such conditionals are primarily understood as conveying a relevance relation between a possibility expressed by the antecedent and the (putative) fact expressed by the consequent. See section 8 .

${ }^{4}$ Among constraints concerned with epistemology or psychology, the best known is probably Ernest Adams' (1975) proposal that the degree of credence that a person gives to an indicative conditional, "if P, Q" is the person's subjective probability of Q on the supposition of P. I do think that the explanatory model developed here can explain the intuitions that do conform to Adams' proposal, but since I think that the proposal is problematic for a wide range of cases and since a proper discussion of these cases and of subjective conditional probabilities would require too much space, I will focus on the requirement that the material implication holds. (We will note some exceptions to that requirement too, but they are considerably easier to deal with.) Problems for Adams' proposal include: (I) Conditionals that do not seem truth-evaluable, such as (15) and (33). (II) Conditionals that intuitively convey that the consequent follows from the antecedent but have consequents that have a fairly high probability independently of the antecedent (Lycan 2001: 70). For example, I find it 50\% likely that I will have a cup of tea before going to bed and $90 \%$ likely that it will rain tomorrow, independently of whether I go to bed or not, but the following seems false:

(i) If I have a cup of tea before going to bed, it will rain tomorrow.

For some further difficulties for Adams' proposal, see Morton (2004). 
The third striking feature is that, for "If P, Q" to seem felicitous, it is typically not enough that some such general constraint is satisfied: some relation of the right sort between $\mathrm{P}$ and $\mathrm{Q}$ needs to be made salient enough, as it is in examples (1) through (14). For example, even if I find it highly likely both that Berne is the capital of Switzerland and that John Lennon was killed in 1980, I am not thereby ready to accept (or reject) the truth of:

(15) If Berne is the capital of Switzerland, John Lennon was killed in 1980.

Apparently, to agree with (15), it is not enough that one should find it likely that the material implication holds. ${ }^{5}$ Moreover, the reason that (15) fails to be clearly truth-evaluable is not (or not just) that it violates conversational maxims by stating something weaker than could be stated given that both antecedent and consequent are highly likely, namely, the conjunction of antecedent and consequent. Trivialities do not in general seem nonsensical: although people seem to think that the utterance of "I weigh more than 3 pounds and more than 2 pounds" is puzzling, they also think that what is said is obviously true in a way that (15) is not. At the same time, it is clear that pragmatics plays a crucial role in explaining why conditionals like (15) resist truth-evaluation. Suppose that we are playing a game where we are handed two cards, one of which contains falsehoods and the other truths, and that our objective is to decide which card is which. In a context where we have found both antecedent and consequent on the same card, (15) would seem to express an epistemic consequence relation and would seem unproblematically true.

The challenge then is to characterize both the conventional contribution of the "if P, Q" form and the pragmatic processes through which the constrained diversity of contents is derived. A full characterization would demand answering a number of difficult questions: To what extent, if any, is the lexical item if ambiguous? Is the conventional contribution of ifclauses to consequence conditionals like (1), (2) and (3) different from the contribution of such clauses to other conditionals: independence conditionals like (4), relevance conditionals like (5), conditional speech act constructions like (6) and (7), modal conditionals like (9), perspective shifters like (10), (11) and (12), "cautious" speech act conditionals like (13) and (14)? Can some of these, or all, be understood as pragmatic enrichments of a weaker, more abstract conventional content? If they can, is that conventional content truth-evaluable, or is

\footnotetext{
${ }^{5}$ Nor is it enough that one's subjective probability that John Lennon was killed in 1980 is high on the supposition that Berne is the capital of Switzerland.
} 
pragmatic enrichment needed to reach a minimal truth-evaluable content, as examples like (15) suggest?

In what follows, I will begin to argue for a contextualist account of conditionals according to which the conventional contribution of the if-clause radically underspecifies the relation between antecedent and consequent intuitively expressed by the containing sentence. The argument takes the form of an inference to the best explanation, building on an uncontroversial assumption about the conventional contribution of if-clauses. This assumption, non-truth-presentational introduction, is that an if-clause introduces a proposition without presenting it as true so that the main clause can be understood in relation to it. I will suggest that the constrained variability of intuitive relations expressed by conditionals can be explained given non-truth-presentational introduction and the assumption that the content intuitively assigned to a given conditional involves the relation that is made most immediately salient by antecedent and consequent given that contribution. Since no further assumptions need to be made about the conventional contribution of if-clauses, there is no need to postulate any such further contribution. The upshot is that conditionals have no truth-evaluable or intuitively complete content absent some contextually provided salient enough relation between antecedent and consequent. I call this view relational contextualism.

A full argument would obviously have to look at competing explanations of the phenomena and show in some detail how these explanations are less satisfying. I have taken steps in that direction elsewhere ${ }^{6}$ here, my main concern is to present the central pieces of my own positive explanation. Even if the comparative part of the argument should fail, however, I think that the explanations provided here will prove fruitful for those trying to understand conditionals and their role in reasoning and discourse. Since the pragmatic explanations build on a minimal, uncontroversial assumption about the conventional contribution of the ifclause, they are also likely to be available to theories that make more substantive assumptions.

The organization of the essay is straightforward. In the next section, I make some preliminary remarks about factors that might affect the salience of relations between antecedent and consequent, and present non-truth-presentational introduction. In later sections, I look at different sorts of relations that conditionals are likely to make salient given this minimal conventional contribution, and explain how conditionals expressing these

\footnotetext{
${ }^{6}$ Björnsson $(2007,2008, \mathrm{~ms} 1, \mathrm{~ms} 2)$
} 
relations display just the behavior we expect. Before closing, I summarize the findings and discuss, very briefly, to what extent the argument supports relational contextualism.

Two major restrictions of the discussion should be noted. First, to limit the discussion, the examples discussed will all be of what is commonly classified as indicative conditionals. I have nothing to say here about the contribution of subjunctive or counterfactual forms, though I argue elsewhere that relational contextualism is well placed to accommodate such contributions and explain the peculiarities of counterfactual thinking. Second, I will say nothing here about the syntax of conditionals, or conventional restrictions on the syntactic role played by if-clauses; the concern here is with the contents conveyed by if-conditionals. ${ }^{8}$

\section{Preliminary remarks about the pragmatics of if-conditionals}

It is uncontroversial that pragmatic considerations play a crucial role in the interpretation of conditionals. The case of (15) illustrates how context might be needed to make conditionals intelligible, but it is clear that pragmatic considerations guide our understanding of relations between antecedent and consequent of the kinds exemplified by (1) through (14). For example, just about any declarative conditional can be understood as expressing either an epistemic or a causal consequence relation, given the right context. Consider (5) set in a context where it is believed that the addressee's hunger is a sure sign that there is a certain kind of food in the kitchen, or (11) set in a context where a magical book follows one's gaze around; or consider (9) set in a context where the rules of etiquette are such that a certain conversational topic calls for certain menu choices. Whatever the correct account is of the conventional contribution of the if-clause, there is no doubt that contextual factors affect the interpretation.

It is equally uncontroversial, and well illustrated by (1) through (14), that the contents of the if-clause and the main clause play an important role in determining what relation between the two we take the conditional to convey. Apparently, we attribute a relation of causal consequence when the two contents are of a sort that are likely to stand in that causal relation; we attribute a relation of relevance when it seems likely that the content of the main clause would be relevant to a need or goal indicated by the if-clause, and so forth. This illustrates that an important role is played by general expectations about what sort of relations hold

\footnotetext{
${ }^{8}$ Björnsson and Gregoromichelaki (forthcoming)
} 
between different conditions, or between conditions and speech acts. Moreover, we have already noted that expectations about relations holding in a particular context can affect interpretations, thus, e.g., changing (5) from a relevance conditional to a consequence conditional.

The question, though, is why and how these factors play a role, and in particular what the conventional contributions of if-clauses are that mandate that role. I have already introduced the main thesis of this essay: Our intuitive grasp of the following fact about conditionals both allows for the role of the various pragmatic factors and accounts for the strong restrictions on interpretations of conditionals:

Non-Truth-Presentational Introduction: If-clauses introduce a proposition without presenting it as true so that the main clause can be understood in relation to it. ${ }^{9}$

Given the intended weak reading of "in relation to", non-truth-presentational introduction is true on any plausible account of the conventional contribution of if-clauses. In fact, it states what might be the most obvious facts about if-clauses: that they introduce a proposition, that they can be used in contexts where that proposition is not known to be true, and that they relate to their main clauses.

Controversy ensues when the relation in question is specified by different theories. According to the material implication analysis of conditionals, the conventional meaning of "if $\mathrm{P}$, Q" is the truth-condition $\neg(\mathrm{P} \wedge \neg \mathrm{Q}) .{ }^{10}$ According to possible worlds analyses, the conventional meaning is that $\mathrm{Q}$ holds in all relevant, or the closest, possible world(s) in which P holds. ${ }^{11}$ According to illocutionary theories, it is that $\mathrm{Q}$ is asserted under the supposition

\footnotetext{
${ }^{9}$ Depending on how propositions are understood, this might need qualification to cover habitual or generalized conditionals, such as "if it rained, we stayed indoors playing cards" or "if a dog barks, it feels threatened", meaning roughly "whenever it rained, we stayed indoors playing cards" and "whenever a dog barks, it feels threatened". In such conditionals, the if-clause introduces a "gappy" proposition that is true or false only relative to a certain time or a certain individual. (If one wants to think of propositions as bearers of non-relative truth, non-truth-presentational introduction needs to be reformulated in terms of their gappy not-quite-propositional relatives.) However, the discussion here will be almost exclusively concerned with particularized conditionals.

${ }^{10}$ Grice (1975), Smith and Smith (1988), Noh (1998) Allott and Uchida (2009). Jackson (1987) defends the idea that material implication exhausts the truth-conditional conventional meaning of indicative conditionals, but thinks that there is a further constraint on acceptability.

${ }^{11}$ Stalnaker (1981), Nolan (2003)
} 
that $\mathrm{P} .{ }^{12}$ Finally, according to expressivist theories, the conventional meaning is given by the epistemic condition that the credence assigned to "if $\mathrm{P}, \mathrm{Q}$ " is the probability of Q conditional upon $\mathrm{P}^{13}$

What I will argue, in effect, is that none of these further characterizations of the conventional contribution of if-clauses are needed to explain constraints on the contents of conditionals. The reason is that introducing a proposition without presenting it as true activates a restricted range of cognitive or conversational purposes that provide an immediate cognitive context for the interpretation of the relation between antecedent and consequent. Only relations that are relevant to those purposes will seem to be part of the content of the conditional. Furthermore, only some relations relevant to these purposes are straightforwardly activated without added qualifications. In particular, relations that are straightforwardly activated by declarative conditionals either support modus ponens or imply that the consequent is categorically presented as true, thus implying the material implication (with some interesting exceptions).

The cognitive context into which we most often introduce propositions without presenting them as true is that of contingency planning. In sections 4 through 8 , we will look at a number of relations that are especially salient in that context, in particular relations of consequence, independence and practical relevance. The vast majority of conditionals express one of these relations, and in particular the relation of consequence.

\section{Consequence}

Contingency planning largely consists of thinking about what might be the case or might be done, and what follows from that. To understand contingency planning, then, we need to understand our thinking about one thing following from another, or thoughts involving the consequence relation. One might suspect that the consequence relation is in turn best understood in terms of conditionals: to think that $\mathrm{Q}$ follows from $\mathrm{P}$ is to think that if $\mathrm{P}$ is the case, $\mathrm{Q}$ is the case. However, given that conditionals often do not express a consequence relation between antecedent and consequent, we still need an analysis of the thoughts involved in the relevant conditionals, i.e. those that concern a consequence relation. In what

\footnotetext{
${ }^{12}$ Edgington (1995: 287-291), Barker (1995), Bennett (2003: 124-126), Barnett (2006)

${ }^{13}$ Edgington (1995), Bennett (2003: chs. 4-11)
} 
follows I will suggest a way to understand such thoughts that fits with a plausible view of human cognition and is detailed enough to make intelligible the relation between such thoughts and conditionals.

To ease the exposition, I will use "A" and "B" as dummy predicates, and use " $A$ *" and " $\mathrm{B}^{*}$ " as names for propositions to the effect that some particular individual or ordered n-tuple is $\mathrm{A}$, or that it is $\mathrm{B}$, respectively.

To understand consequence relations and thoughts concerning such relations, start with the notion of a regularity fact - a fact to the effect that, within a certain domain, everything that is $\mathrm{A}$ is $\mathrm{B}$ - and the notion of the supporting conditions of such a fact - the conditions that define its domain. A regularity fact is especially interesting when (i) B is true about some but not all elements in its domain, and (ii) we can learn that it obtains and reliably identify elements of its domain as falling within that domain prior to establishing for each instance whether it is A or B. Call such regularity facts "lawlike".

Lawlike regularities might involve causes and effects (measles and fever), or two effects of the same cause (barometer falls and precipitation), or events in separate but regular processes (the departures of the Red Line and the arrival within five minutes of Bus 5), but also facts standing in mathematical or logical relationships (the dividend's being a prime and the quotient's not being an integer; a conjunct's being false and the conjunction's being false). Some lawlike regularities are non-probabilistic laws without domain restrictionsmathematical and logical regularities, most clearly. Others hold for macroscopic objects within restricted spatiotemporal domains, say, or have supporting conditions with an irreducible ceteris paribus character that exclude "freak occurrences", or range over domains that are in some sense fundamentally indeterminate. ${ }^{14}$ Moreover, many lawful regularities are regularities of statistical events to the effect that whenever something is the case, the probability for (relative frequency of) something else is such and such.

Keeping track of and relying on various kinds of lawlike regularity facts and their domains is a fundamental cognitive task for any creature capable of adjusting its behavior to the circumstances and of learning new ways of doing so. This task relies on two capacities. It

\footnotetext{
${ }^{14}$ For this reason, one might think that physics is fundamentally indeterministic but still think that the fact that the ball fell to the floor followed from the fact that it was dropped: there is a universal correlation between these two kinds of events when things are arranged thus and so and no freak event occurs. Should the ball remain midair or fly sideways and land on the sofa, that is a freak event, meaning that the case is outside of the domain of the regularity.
} 
requires, first, a reliable mechanism that produces inferences from $A^{*}$ to $B^{*}$ and from $\neg B^{*}$ to $\neg \mathrm{A}^{*}$, and, second, a reliable capacity to identify elements of the relevant domain. We can call this recognitional and inferential ability a concept of the regularity fact in question, and we can say that the elements of its domain fall under or satisfy this concept.

Possessors of a regularity concept need not have correct or even explicit representations of the relevant $\mathrm{A}$ and $\mathrm{B}$ or the supporting conditions of the regularity. We often begin forming a regularity concept after encountering a few instances, only later learning exactly what conditions it relies on and the nature of the related properties. In many ways, learning about a regularity is like learning about a natural kind. Our primary way of learning about regularities is presumably through exposition to a wealth of its instances and induction-like processes. But a number of other ways are available: we can encounter a single instance of the regularity and recognize it as a case of a more general kind of regularity, thereby forming a concept of the specific lawlike regularity (learning that command $+\mathrm{w}$ closes the active window by seeing it happen once and taking it to depend on the normal designed functioning of the operating system, whatever that might be); we can similarly use knowledge of general regularities to deduce local regularities; we can quite simply be told that a certain kind of event is universally or most often accompanied by another kind of event, thus inheriting the concept from someone else who has actually encountered the regularity or done the deduction; or we can form such a concept in response to hearing a conditional ("if you press command $+\mathrm{w}$, the active window is closed"). The last case is a bit like seeing a particular instance of a regularity as an instance of a more general kind of regularity, and a bit like being told explicitly that there is a certain kind of regularity that ranges over the present case.

Suppose that this story is roughly correct. Then it seems plausible that when we pretheoretically think that a certain case is such that $\mathrm{A}$ implies $\mathrm{B}$, or that $\mathrm{B}$ follows from or is a consequence of $\mathrm{A}$, we are taking that case to fall under the concept of some lawlike regularity. Moreover, it would be no wonder that consequence relations are highly relevant to the central cognitive interests we have in non-truth-presentational introductions of propositions, and so no wonder that this is what we intuitively take most conditionals to convey.

Taking a certain regularity concept to apply in a particular case disposes us to employ the concept's capacities in relation to that case. Most obviously it disposes us to infer B* from $A^{*}$ and $\neg \mathrm{A}^{*}$ from $\neg \mathrm{B}^{*}$, but it also disposes us to learn from the case at hand about the domain of the regularity, extending these dispositions to cases that strike us as relevantly alike. In order for these dispositions to reliably lead to true conclusions and further correct applications of 
the concept, the case at hand needs to actually fall within the domain of the regularity. In taking a regularity concept to apply in a particular case, then, we are in effect assuming, first, that within the domain of the regularity everything that is A is B and, second, that the case at hand falls within that domain. If we let $C$ be the supporting conditions for the regularity and $s$ the case at hand, what we are assuming can thus be said to have the following form:

REG: $\quad(\mathrm{x})((\mathrm{Ax} \wedge \mathrm{Cx}) \supset \mathrm{Bx}) \wedge \mathrm{Cs}$

What I suggest, then, is that when we think that one condition follows from another in a certain way, these are the correctness or truth conditions of that thought. ${ }^{15}$

Given this suggestion, it is clear why ordinary consequence conditionals support modus ponens and imply material implication. But other relations between propositions that do not support modus ponens are nevertheless highly relevant to contingency planning in much the same way. I have already indicated that regularity facts can relate probabilistic propositions and they can equally relate possibilistic propositions; such relations are naturally conveyed using conditionals with appropriately qualified clauses:

(16) If Sarah is not in her office, she has probably talked to Jane.

(17) If Sarah is not in her office, she might have talked to Jane.

However, makes it probable or makes it epistemically possible are not salient candidate interpretations of the relation expressed by (18):

(18) If Sarah is not in her office, she has talked to Jane.

If they were, modus ponens would not be supported. ${ }^{16}$ The question, though, is why they are not, given our guiding assumption that conditionals express relations that are particularly

\footnotetext{
${ }^{15}$ Notice that such a thought involves no individual concepts of other elements in the regularity's domain than $s$. This is why, on this account, thoughts about what follows from what are unlikely to seem to be about actual regularities, but rather about abstract relations between universals.

Talk about what needs to be the case for applications of a regularity concept to "reliably" lead to true conclusions and further correct applications of the concept can perhaps best be spelled out in historical, etiological terms: our continued employment of regularity concepts is explained by the fact that they tend to successfully guide actions in ways that rely on the successful tracking of regularities and location of cases within their domains (see e.g. Millikan 1984, 2000, 2005).

${ }^{16}$ Probabilistic cases raise a host of difficult problems that I cannot deal with here. Edgington $(1995,2008)$ has argued that various truth-conditional theories are unable to account for probabilistic judgments about conditionals. I try to argue
} 
relevant to contingency planning. After all, relations of making probable or making possible are both highly relevant for such planning. And once the question is raised, it should be raised about relations of exclusion, naturally expressed using negated consequents:

(19) If Sarah is not in her office, she has not talked to Jane.

Again, we might ask why, if a relation's pragmatic relevance to contingency planning is what leads us to interpret a conditional as expressing it, we cannot see (18) as expressing what is expressed by (19), and thus as certainly not supporting modus ponens. Absent such an answer, the general pragmatic story looks implausible, in need of further conventionally given constraints.

There is a plausible answer, however, and one that covers all three alternative relations: making probable, making possible and excluding. Contingency planning and hypothetical thinking involves constructing representations of alternative scenarios. When we construct a scenario where Sarah is not in her office and take her having talked to Jane to be a consequence of that, our scenario now contains the conjunction of antecedent and consequent, unqualified. However, if we take Sarah's having talked to Jane to merely be made probable or possible, or as being excluded by Sarah's not being in her office, something more complex is needed. In the last case we need to negate the consequent before forming the conjunction; in the former cases we might need to handle two scenarios in our planning, one involving the antecedent and the consequent and the other the antecedent and the negation of the consequent, or perhaps something like a decision theoretic action tree with the consequent on one branch and its negation on a sister branch. In either case, the qualifications involved in (16), (17) and (19) correspond to qualifications that we need to make when we represent alternative scenarios in our contingency planning. Since the qualifications are highly relevant to contingency planning and since they are not marked in (18), the unqualified consequent prevents the alternative interpretations. (Compare charade communication: having symbolized, in turn, a crocodile and hunger, the audience might take the message to be that the crocodile is hungry, but not that the crocodile might be or probably is hungry, or that it is not hungry.)

\footnotetext{
elsewhere that the full set of phenomena, including cases that pose troubles for Edgington's view (see Morton 2004), is adequately dealt with using a contextualist account of the sort defended here.
} 
Although REG supports modus ponens, and although I have argued that consequence conditionals express content of that form, we should note that the story here allows for conditionals that do not: depending on context, it might be clear that the supporting conditions are not unqualifiedly presented as true. Here is one telling example, adapted from Allan Gibbard, via Bill Lycan (2001, 63):

(20) I'll respond politely if you insult me, but I won't if you insult my wife.

Suppose that the addressee proceeds to insult both the speaker and his wife, and that the speaker's response is very impolite. Intuitively, this is perfectly consonant with what has been said, but then the first conjunct cannot support modus ponens: it has a true antecedent but a false consequent. What goes on here, it seems, is that the speaker does not assert that all the supporting conditions hold for the relevant consequence relation, only some relevant subset. ${ }^{17}$

Once we begin thinking about such cases, it seems possible that many consequence conditionals only present part of their supporting conditions as true. Suppose that I tell a friend who needs to go to the airport that he will be there with plenty of time to spare if he leaves three hours before departure, but that a major earthquake blocks both railway and roads leading to the airport for several days. At the very least, it is not completely clear that my utterance implied that there would be no earthquake (or that my friend wouldn't be hit by a car when crossing the street to fetch a taxi, or that he wouldn't die of a heart attack just after leaving). Obviously, this point generalizes to other consequence conditionals with supporting conditions that might be undermined by freak events that both speakers and hearers can justifiably ignore. ${ }^{18}$

If this is correct, one sort of qualified consequence relation might be communicated without explicit qualifications of the conditionals, and that might seem to contradict our previous explanation of why makes probable and excludes typically require such qualifications. But this sort is different: in constructing representations of scenarios for contingency planning we regularly do disregard freak occurrences unless their possibility has

\footnotetext{
${ }^{17}$ The conditional promise aspect of (20) is inessential to the phenomenon:

(i) I know these gals: they are tough but not irresponsible. They'll play an even tougher game if it is raining or sleeting, but they'll stop immediately if there is lightning.

${ }^{18}$ For further discussion of counterexamples to modus ponens from a contextualist point of view, see Lycan (2001, 57-69). Although Lycan's event theory provides a very different semantic framework for consequence conditionals than that offered here, most of his points translate with only minor adjustments.
} 
been explicitly raised. They are not part of our representations of possibilities, but rather of a general understanding that such representations are simplifications.

\section{Independence}

We now have a pragmatic explanation of why, given non-truth-presentational introduction, conditionals will be taken to express consequence relations that support modus ponens (at least under normal circumstances), but not similar but weaker relations. However, there is another class of relations that are highly relevant to contingency planning but resist this explanation. These are independence relations, expressed in conditionals like (4) above and in (21) and (22) below:

(21) If you ignore him, he'll still adore your.

(22) Even if we downsize, we still have to pay the computer licenses.

Intuitively, such conditionals convey that the consequent holds independently of the antecedent. In most cases, such interpretations depend on semantic markers like "even" or "still". Contrast (21) and (22) with (23) and (24), which seem to force consequence readings:

(23) If you ignore him, he'll adore your.

(24) If we downsize, we have to pay the computer licenses.

However, the requirement of semantic markers cannot be explained with reference to a need for corresponding explicit markers in our representations of hypothetical scenarios, as in the case of probabilistic, possibilistic or exclusionary relations: the hypothetical scenarios reflecting independence conditionals will contain the conjunction of antecedent and consequent, unqualified, just as for consequence conditionals. If our explanation of why consequence conditionals need no marker is correct, there must be some other explanation of the requirement in the case of independence conditionals.

A first suggestion invokes the ubiquity of independence relations: any arbitrary fact is causally and epistemically independent from just about every other fact. Perhaps, then, independence interpretations are not naturally available for (23) and (24) because they do not stand out. Compare pointing: if I point and say "look at that" but there is nothing particularly remarkable in the direction of my finger, my interlocutors might not get what I am referring to. In comparison, consequence relations are much more telling. But this cannot be the whole story; if it were, independence interpretations should be easily available when the 
independence relation does stand out, and cases suggest that is not enough. The independence relation expressed by (21) is out of the ordinary, but still not available for the interpretation of (23).

Something more is apparently needed to explain the requirement of markers, and I suspect that the complete explanation involves the fact that explicitly or consciously thinking that B holds independently of $\mathrm{A}$ is a much more complex state of mind than thinking that $\mathrm{B}$ is a consequence of A. For that reason, it needs more specific prompting to be activated by an utterance and for the independence relation to be made salient.

Because of the ubiquity of independence relations, we most likely operate with a general presumption of independence. If we think that $\mathrm{B}^{*}$ and do not take some $\mathrm{A}^{*}$ to affect the probability of $\mathrm{B}^{*}$, we reason and act as if $\mathrm{B}^{*}$ holds independently of $\mathrm{A}^{*}$, even if we have no explicit representation of this particular independence, or perhaps not even an explicit representation of $A^{*}$. This morning, for example, I thought that I would be working on this essay, and I presumably acted as if this was independent of whether my left and right hands would touch during breakfast. But I had no explicit or conscious thought that working on the essay was independent of hand touching.

Given that independence is a default assumption, conscious or explicit thoughts to the effect that $\mathrm{B}^{*}$ is independent of $\mathrm{A}^{*}$ would consist in the conscious or explicit representation of a negative outcome of an explicit test for dependence, or the negation of claims of dependence. Contrast this with the thought that $A^{*}$ implies $B^{*}$, which, I have suggested, consists in the simple activation of a basic inferential mechanism. Because of this contrast between our explicit thoughts about independence relations on the one hand, and about consequence relations on the other, we can expect the activation of the former to need much more specific prompting. It thus makes sense that conditionals are not easily understood as conveying independence relations in the absence of markers like "even" or "still". 20

\footnotetext{
${ }^{20} \mathrm{By}$ contrast, it is unclear whether explicit representations of possibilistic and probabilistic relations must be more complex than representations of consequence relations; what seems clear, and what I appealed to in the previous explanation, is that the hypothetical scenarios built from such relations must be more complex than those built from consequence relations.

Notice that the claim here is that the comparative inaccessibility of independence relations as contents of conditionals is not merely due to their ubiquity. I am not saying that there cannot be unmarked independence conditionals; there are: "Don't worry, they're a tough bunch. They'll play Saturday if it is raining, for sure." However, those that seem most natural typically involve appended rather than prepended if-clauses, again showing that independence relations are less accessible than consequence relations, which are naturally expressed in both orders. (One might wonder why the consequence relation becomes more prominent with prepended than with appended if-clauses. I see two possible reasons. One is that an appended
} 
One would of course want to know just how such markers point us towards an independence relation. This is not the place to fully analyze these markers - there is considerable literature on the topic - but it is intuitively clear how they do their job. "Even" seems to indicate that its target was less likely to figure in the relevant context than some relevant alternative(s): "Even Granny had some of the wine" indicates that Granny was less likely than some relevant others to have some of the wine; "Granny even had some wine" indicates that having some wine was less likely than some relevant alternative activities of hers. When "even" modifies conditionals, it seems to indicate that the consequent is less likely given the if-clause than given some relevant alternative condition: "The light is on even if you flip the switch down". ${ }^{22}$ Similarly, "still" indicates constancy in one dimension across change in another (time, space, events, conditions), conversationally implying that such constancy might not have been the case: "Farther east, the forest is still dense"; "Granny is still singing"; "It was better than the last one, but still not good enough". In conditionals indicating independence, the implied constancy is across relevant possible conditions, one among which is indicated by the antecedent: "If you take the scenic road, you will still be there on time". Other locutions indicating constancy can serve the same function, at least in

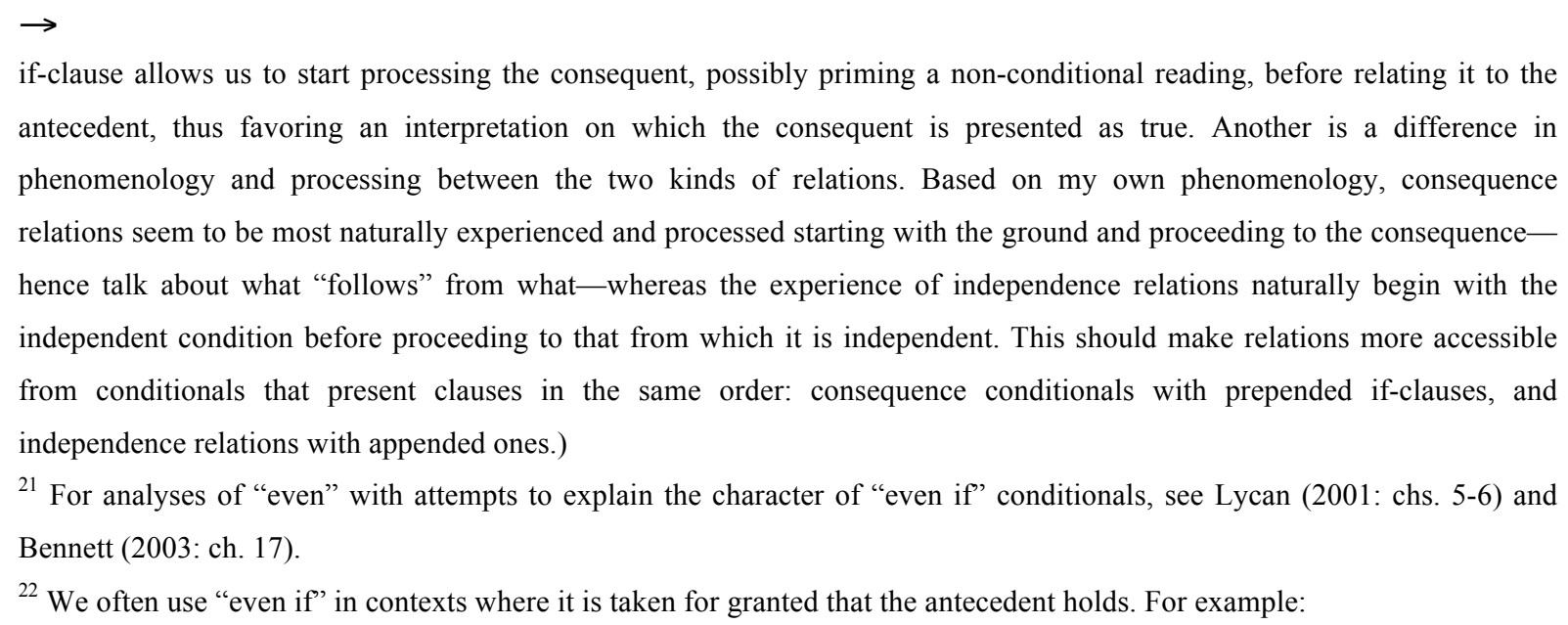

if-clause allows us to start processing the consequent, possibly priming a non-conditional reading, before relating it to the antecedent, thus favoring an interpretation on which the consequent is presented as true. Another is a difference in phenomenology and processing between the two kinds of relations. Based on my own phenomenology, consequence relations seem to be most naturally experienced and processed starting with the ground and proceeding to the consequencehence talk about what "follows" from what-whereas the experience of independence relations naturally begin with the independent condition before proceeding to that from which it is independent. This should make relations more accessible from conditionals that present clauses in the same order: consequence conditionals with prepended if-clauses, and independence relations with appended ones.)

${ }^{21}$ For analyses of "even" with attempts to explain the character of "even if" conditionals, see Lycan (2001: chs. 5-6) and Bennett (2003: ch. 17).

${ }^{22}$ We often use "even if" in contexts where it is taken for granted that the antecedent holds. For example:

(i) Even if we know that there are some people who are happier, ... we also know that they rarely become so by being educated as outlaws (Williams 2006, p. 48).

(ii) Even if liberty or freedom of this kind is something to write home about, it is so only when one feels obliged to write and has nothing momentous to report (Mele 2009, 84).

It is noteworthy that "If P, still Q" conditionals do less well in communicating the truth-presenting nature of the if-clause in such contexts. The explanation, I suggest, is that our primary interpretive task with "even if" conditionals is to find the relevant comparison between the targets for "even" and some relevant class of comparison objects, providing a context where the introduction of a proposition not presented as true indicates that the relevant comparison is between possibilities. This removes the pressure to identify some other purpose for the non-truth-presentational introduction, including the purposes of contingency planning, expression of uncertainty and perspective taking. 
the right context: "stay", "continue", "go on", "remain": "If I flip the switch down, the light stays on", "The game will continue if it starts to rain", "Life will go on if she leaves you, you know", "If the battle is won, the war remains". 23

If this is right, then independence conditionals would seem to represent contents of the following shape:

IND: $\quad(\mathrm{x})\left(\left(\left(\mathrm{A}_{1} \mathrm{x} \vee \mathrm{A}_{2} \mathrm{x} \vee \ldots \mathrm{A}_{\mathrm{n}} \mathrm{x}\right) \wedge \mathrm{Cx}\right) \supset \mathrm{Bx}\right) \wedge \mathrm{Cs}$

Intuitively: the case is such that B holds in all such cases in which some from a range of alternative conditions, $A_{1}$ through $A_{n}$, hold. When the alternative conditions are exhaustive, the independence relation implies that $\mathrm{B}$ holds in the case and that the conditional is a "semifactual", implying the truth of its consequent. ${ }^{24}$

I will mention one more semantic marker that seems capable of suggesting an independence relation: negation. Here are three typical examples:

(25) If you don't invite him to the party, he won't blame you.

(26) The substance won't ignite if you touch it.

(27) If you ask him, he won't bite your head off. ${ }^{25}$

Given the right context, these conditionals could be understood as consequence conditionals, but the contents of the two clauses strongly invite an independence reading. Even without recourse to "even", "still" or relatives, such readings seems comparatively accessible when consequents are put in negative terms. The question is why.

One possible explanation of why negative consequents make independence relations more easily accessible is that, unlike their positive counterparts, they contain the explicit

\footnotetext{
${ }^{23}$ Relatedly, independence relations can be expressed using pairs of conditionals, as in "You are damned if you do, and damned if you don't." In such cases, though, neither consequence nor independence relations are expressed by the individual conditionals. Rather, they express a relation that seems to be neutral with regard to consequence and independence: a relation of "accompaniment", we might say.

${ }^{24}$ The expression "semifactual” comes from Goodman (1947: 114-115). Se also Lycan (2001: 20-21, 31-36).

The following might be an example where the alternative conditions are non-exhaustive: "Even if we beg with a pretty 'please', he still won't help. We need to pay him."

Like consequence conditionals, independence conditionals need not express that all supporting conditions of the consequence relation hold. Here is the example from which (20) was derived: “I'll be polite even if you insult me, but I won't be polite if you insult my wife" (Lycan 2001: 63).

${ }^{25}$ Lycan (2001: 21); for an early treatment, see Davis (1983), who calls conditionals without a-temporal "then" at the beginning of the main clause "weak".
} 
representational elements of their contradictions: representing that the substance will not ignite already involves representing that the substance will ignite, since this is the representation that the negation operates on. (The kindergarten illustration of this phenomenon is the exhortation not to think of a pink elephant, the uptake of which already involves a violation.) This in turns suggests that the conditional will prime representations of possible relations not only between antecedent and consequent, but also between antecedent and the positive counterpart of the negative consequent. If it is more plausible that a consequence relation would hold between the latter, the relation between antecedent and consequent will in turn be seen as an independence relation that rules out that consequence relation. However, if it is more plausible that a consequent relation would hold between antecedent and consequent, that is still how the conditional is read:

(28) If you ignore him, he won't adore your.

(29) If we downsize, we will not have to pay computer licenses.

\section{Embedding and its limits}

Examples like (15) (“If Berne is the capital of Switzerland, John Lennon was killed in 1980”) show that "if P, Q" constructions are likely to strike us as unintelligible unless they make immediately salient some relevant relation between P and Q. On the other hand, it is clear that we can understand conditionals while having a very thin grasp of the sort of relation expressed. Consider:

(30) Kripke was there if Strawson was.

Apart from our lack of knowledge about the referent of "there" and the relevant time, this conditional seems intelligible enough even though we have no definite idea about how Kripke's presence was tied to Strawson's and no idea of whether Kripke's presence at the event is supposed to be causally or merely epistemically related to Strawson's. Perhaps Kripke was eager to talk to Strawson, or perhaps Strawson only went to one event of the relevant kind during the relevant period, and met Kripke there?

The reason why (30) strikes us as intelligible and truth-evaluable (but not by us), whereas (15) does not in the absence of a special context, seems to be that the former triggers representations of ways in which the consequent follows from the antecedent. No definite consequence relation comes to mind, but rather a somewhat vague disjunction of such 
relations. If we can rely on the obtaining of those vague and disjunctive consequence relations, we know enough to run modus ponens and modus tollens on (30). For that restricted purpose, even a vague and disjunctive idea of values for the contextual variable might be salient enough. ${ }^{26}$

The possibility of understanding a paradigmatic conditional with only a vague or disjunctive content in mind solves a well-known puzzle concerning conditionals embedded in various contexts, such as in antecedents of other conditionals. On the one hand, many such constructions involving consequence or independence conditionals seem perfectly intelligible:

(31) If Jack will be happy if you hold his hand, he will be ecstatic if you give him a kiss.

(32) If they will play even if it snows, they are tougher than I thought.

On the other hand, some are very hard to grasp, even though the embedded conditional is not. Take the standard illustration, from Allan Gibbard (1981: 235):

(33) If Kripke was there if Strawson was, then Anscombe was there.

The antecedent here contains (30), and both it and the consequent seem to make sense independently. (33) as a whole does not, however. This contrast has been taken to suggest that there is no general way of decoding embedded conditionals, and thus to provide prima facie evidence that conditionals lack truth-conditions. ${ }^{27}$ But occasional failures to embed is just what we should expect given relational contextualism, that is, given that truth-evaluable contents are assigned pragmatically. The reason that (33) seems unintelligible is simply that our vague and disjunctive understanding of (30) makes the antecedent of (33) correspondingly indeterminate. Because of this, it is very hard to see how it might relate to the consequent, for it is hard to see how the consequent could follow from such an indeterminate affair. (33) appears to be almost completely unintelligible for the very same reason that (15) does: it does not make immediately salient any relevant enough relation. Given this account, the seeming unintelligibility of certain embedding constructions only provides another

\footnotetext{
${ }^{26}$ That doesn't mean, though, that we understand conditionals as having more specific contents by first grasping these nonspecific relations and then pragmatically enrich them. In most contexts, more specific relations will tend to be more salient, and thus more likely to attract our interpretation mechanisms.

${ }^{27}$ Edgington (1995: 280-284), Bennett (2003: 95-102), Barnett (2006: 548)
} 
illustration of the fact that some conditionals lack definite enough contents to be truthevaluable.

\section{Epistemic context dependence}

According to the guiding hypothesis of the last sections, the interpretation of conditionals is constrained by the assumption that the relation between antecedent and consequent is relevant to the purpose of non-truth-presentational introduction of the if-clause. Given this constraint, I have argued, we should expect most conditionals to be consequence conditionals, and to support modus ponens. This provides the beginning of an explanation of the central logical properties of conditionals. In this section, I will argue that the same assumption lets us understand the way in which indicative conditionals are sensitive to epistemic perspectives.

Consider the following so-called stand-off case: a case where two conditionals with identical antecedents and incompatible consequents might be perfectly appropriate in their respective contexts. ${ }^{28}$ Ann and Beth both know that the treasure is hidden in one of three chests, C1, C2 and C3. Each has a quick peek inside one of the chests, but cannot communicate her finding to the other. Ann peeks inside C3 and sees that it is empty. Consequently, she accepts (34) below, while rejecting (35):

(34) If the treasure is not in $\mathrm{C} 1$, it is in $\mathrm{C} 2$.

(35) If the treasure is not in $\mathrm{C} 1$, it is in $\mathrm{C} 3$.

Beth, on the other hand, peeks inside $\mathrm{C} 2$ and sees that it is empty. She confidently accepts (35) while rejecting (34). They seem to make opposite judgments, but given Ann's and Beth's epistemic circumstances, each seems correct in her judgment, basing it on true premises and sound reasoning. ${ }^{29}$ Obviously, they make their judgments in circumstances of partial ignorance, and the fact that they are ignorant about different facts explains their different judgments. But each is aware of this ignorance and correctly thinks that it should not undermine confidence in her judgment. In assessing the two conditionals, then, Ann and Beth

\footnotetext{
${ }^{28}$ Gibbard (1981: 231-232)

${ }^{29}$ Edgington (1995: 293-296) Bennett (2003: 83-88)
} 
are clearly not concerned with assessing the same objective state of affairs, but rather with states of affairs that relate, somehow, to their epistemic circumstances. ${ }^{30}$

The literature contains various attempts to understand just what that relation is. One is to say that indicative conditionals express subjective conditional probabilities, rather than representing reality as being a certain way and thus being capable of corresponding or failing to correspond to actual states-of-affairs. ${ }^{31}$ Another preserves the assumption that conditionals have truth-conditions or represent states-of-affairs, but takes the content or truth-conditions of conditionals to involve a relation to the epistemic context in which the conditional judgments are made, or perhaps the epistemic context in which it is assessed. ${ }^{32}$ The explanation that falls out of the current approach is, not surprisingly, that epistemic context can make salient certain relations rather than others but also that it can — sometimes - become part of the very content of the conditional. ${ }^{33}$

The first part of the explanation is that, generally speaking, subjective factors are likely to affect the content we intuitively ascribe to conditionals. For example, different concepts of regularities ranging over antecedent and consequent will be differently accessible depending on whether we think that they apply in the case at hand, since such concepts will be especially relevant to both contingency planning and for inferences about the actual case, other things being equal. If we had believed that barometers magically influence the weather, (36) below would naturally have been understood as expressing a direct causal consequence relation.

(36) If the barometer falls, it will rain.

This provides a plausible explanation of why Ann accepts (34) and Beth (35). Both know that the treasure is in one of two places-Ann that it is in either C1 or C2 and Beth that it is in either $\mathrm{C} 1$ or $\mathrm{C} 3$ - and both know that when something is in exactly one of two places and isn't in the first, it is in the second.

The same explanation does not, however, tell us what content Ann assigns to (35) (or Beth to (34)) before rejecting it. Intuitively, they do not have any definite consequence relation in

\footnotetext{
${ }^{30}$ For example, if Ann had merely been judging whether the corresponding material implication holds, she would not have had grounds for rejecting (35), rather than assigning it, say, a .5 probability.

${ }^{31}$ Adams (1975), Edgington (1995), Bennett (2003)

${ }^{32}$ Stalnaker (1981), Nolan (2003), Weatherson (2009). On Weatherson's view, the proposition expressed by a conditional is a function of the context of assessment, not just the context of utterance.

${ }^{33}$ It thus avoids some of the criticism that Bennett (2003: ch 6) directs at "subjective" theories of the content of conditionals.
} 
mind; rather, what they reject is that there is any consequence relation of the relevant sort. As noted in the previous section, we can attribute vague or disjunctive contents to conditionals as long as the cognitive upshots in the relevant cognitive context are clear enough. Since Ann finds herself in a cognitive context where relations allowing her to infer things about the whereabouts of the treasure are highly relevant, she would thus understand (35) to convey that the consequent follows from the antecedent in some way relevant to such reasoning. When she rejects (35), she is rejecting the idea that any such consequence relation holds. ${ }^{34}$

Her reason for rejecting this is two-fold. First, she knows that the treasure isn't in C3. This fact rules out that Ann could infer the consequent from the antecedent if she should learn that the treasure isn't in $\mathrm{C} 1$, thus blocking the most obvious use of the conditional. ${ }^{35}$ Second, Ann knows of nothing that would allow her to infer that the treasure is in $\mathrm{C} 1$ from the fact that it isn't in C3. Thus, no consequence relation between the two conditions could be relevant in the normal way to her contingency planning: productive use of both modus ponens and modus tollens is ruled out. (Obviously, the same holds, mutatis mutandis, for Beth and (34).)

We have seen, then, how epistemic circumstances affect the content assigned to a conditional in those circumstances, and so affect whether an "if P, Q" construction will seem acceptable or not. In the case where no definite consequence relation could be assigned, the epistemic circumstances could still make it clear enough what sort of consequence relation would be relevant, or that none would, thus providing sufficient ground for rejecting the conditional.

In other cases, the relevance of consequence relations is undermined in more subtle ways. Suppose that Clara is reasonably confident that the treasure is in $\mathrm{C} 1$, and so reasonably confident that it is in either $\mathrm{C} 1$ or $\mathrm{C} 2$. For Ann, confidence in that disjunction inclined her to accept (34), but Clara is unmoved. The reason is not that she knows that the antecedent is false, thus ruling out inferences from antecedent to consequent and making modus tollens redundant, analogously to how Ann's knowledge that the treasure was not in C3 ruled out the employment of any consequence relation expressed by (35). For although Clara is reasonably

\footnotetext{
${ }^{34}$ The pragmatic "definition" should be understood as fixing the reference of the regularity concept rather than as providing essential properties of the regularity. (Compare: In interpreting the sentence "Just as a man entered the room, John fell asleep", we token a concept of an individual man. If the concept has a reference, it must be a man who entered the room, but if there is such an individual, that individual could have been elsewhere, and could have been a woman.)

${ }^{35}$ This is the ground to which people I have presented analogous cases immediately appeal when motivating their rejection of (35) when in Ann's circumstances.
} 
confident that the antecedent of (34) is false, she is not certain. Rather, she lacks inclination to accept (34) because her ground for accepting the disjunction is itself equally strong ground to think that the antecedent is false. Insofar as she relies on this ground, it rules out rationally inferring the consequent from the antecedent; conversely, if she considers the possibility that the antecedent is true, she is simultaneously suspending belief in the grounds for accepting the disjunction. For the same reason, her ground rules out productively or non-redundantly inferring the negation of the antecedent from the negation of the consequent: it supports that conclusion directly, without recourse to modus tollens. Because of this, the consequence relation supported by the disjunction that grounded Ann's acceptance of (34) would be groundless relative to the purpose of contingency planning in Clara's epistemic circumstances, and thus not a candidate for the content of (34). ${ }^{36}$

If I have been correct about the explanation of how Ann's, Beth's and Clara's epistemic circumstances determine what conditionals they accept, it leaves the question of why they would still assign a consequence content to the conditionals and judge that they cannot accept it, rather than think that there is no determinate enough content to accept or reject. The simple answer, it seems, is that the consequence reading is the most accessible, and is accessible enough. In cases where no consequence relation is particularly accessible and where one's epistemic context does not provide definite enough criteria for what a relevant consequence relation would be, acceptance or rejection becomes much less straightforward: this explains reactions to (15) ("If Berne is the capital of Switzerland, John Lennon was killed in 1980"). Similarly where other types of relations than consequence are made somewhat salient:

(37) If you need something to drink later on, the treasure is not in $\mathrm{C} 2$.

(38) If we are only talking about taste, the treasure is in $\mathrm{C} 3$.

\footnotetext{
${ }^{36}$ Instead of straightforwardly rejecting (34), people in Clara's position might well be inclined to rephrase the conditional in probabilistic or possibilistic terms: "If the treasure is not in C1, it might be in C2". The reason, I propose, is that probabilistic or negative judgments about conditionals are easily understood as pertaining to the consequent. Since there is no relevant consequence relation supporting "if the treasure is not in C1, it is not in C2", Clara would be unwilling to reject (34) without qualification.

Notice that Clara's refusal to accept (34) is based on the fact that her reasons for accepting the disjunction are reasons to reject the antecedent, not on her prediction that she would reject the disjunction if she came to believe the consequent. Conditionals like "If he embezzled, we will never know" can be perfectly acceptable and knowable even though we would predictably reject them if we learned that the antecedent was true or the consequent false. The reason is that our grounds for accepting them might do nothing to suggest that the antecedent is false.
} 
Neither (37) and (38) have a clear sense, because the content of their antecedents make salient relations of relevance and perspective, respectively, for which their consequents fail to provide sensible relata. In the case of Ann's interpretation of (35) and Clara's of (34), neither of these problems arise: antecedents invite no non-consequential relation and both Ann and Clara find themselves in salient epistemic circumstances in relation to the treasure and its whereabouts.

Importantly, the explanation of epistemic context dependence offered here does not imply that every difference in epistemic context implies a difference in the intuitive content of the conditional. ${ }^{37}$ People who know that the treasure is in either $\mathrm{C} 1$ or $\mathrm{C} 2$ but not in which of the two can all have the same consequence relation in mind as Ann when tokening (34), independently of various and great differences in epistemic circumstances. Moreover, since we know that Ann's thought is based on this mix of knowledge and ignorance, we can understand the particular consequence relation she has in mind without sharing her particular epistemic context. It is true that epistemic contexts do play a role in fixing the relevant sort of consequence relation, and they seem to play an ineliminable role when conditionals are rejected without being given a definite content, as when Ann rejects (35). However, understanding just what content Ann rejects when rejecting (35) still does not involve grasping Ann's epistemic perspective in its entirety. It is enough to grasp the few aspects of it that I have spelled out here: that she knows that the treasure is not in C3 and lacks reasons to think that it must be in either $\mathrm{C} 1$ or $\mathrm{C} 3$.

Epistemic context dependence also explains one notable sort of apparent counterexample to modus ponens, due to Vann McGee (1985), and a peculiarity of embedded conditionals. Here is a standard version of the counterexample, concerning the 1980 US Presidential election, where Jimmy Carter was trailing Ronald Reagan with Republican John Anderson a distant third. The speaker has not yet heard the results and thinks:

(39) If a Republican won the election, then if it wasn't Reagan who won, it was Anderson.

\footnotetext{
${ }^{37}$ Compare the views of Stalnaker (1981), Nolan (2003) and Weatherson (2009). Also see Bennett's (2003: ch. 6) criticism of subjective theories of conditionals.
} 
This seems to be a perfectly intelligible consequence conditional, and a true one at that. Of course, Reagan did win the election, as the speaker was reasonably confident that he would, and he was a Republican. Still, this and (39) do not seem to provide grounds for thinking that:

(40) If it wasn't Reagan who won, it was Anderson.

This seeming violation of modus ponens is well explained by the pragmatic account on offer here. The embedding conditional is understood as a consequence conditional, and the most straightforward consequence relation takes the antecedent to indicate some of the supporting conditions for the embedded conditional, the remaining supporting condition being that Reagan and Anderson were the only Republicans running; the regularity in question being that whenever there are only two relevant candidates for a certain status and the first candidate does not have that status, the other candidate does. When the embedded conditional is detached, however, that consequence relation is no longer available as a possible interpretation: the speaker's reason to accept the supporting conditions of that consequence relation - his reason to think that a republican won-would be his reason to think that Reagan won, and that reason would undermine both the application of modus ponens and the productive application of modus tollens. (The explanation exactly parallels the explanation of why Clare does not accept (34).) Instead, the most salient ground for ruling out candidates would be reference to polls, where Carter had been doing much better than Anderson.

What this means is that, strictly speaking, there is no violation of modus ponens, since the content of (40) is different from the content of the embedded conditional. ${ }^{38}$ But the example neatly exemplifies how antecedents of conditionals can affect our understanding of the content of consequents; this will be important when we look in section 10 at conditionals the antecedents of which invite perspective taking.

\section{More contingency planning: Relevance, conditional intentions and speech acts}

Thus far, we have seen how the cognitive context of contingency planning creates a strong preference for readings of unqualified conditionals that support modus ponens and modus tollens. We have also looked at some ways in which semantic markers make independence

\footnotetext{
38 This account of what goes on in the McGee case is similar to that provided in Lycan 2001, 66-68, though Lycan understands the scope for context dependence quite differently.
} 
readings of conditionals accessible, and seen how the pragmatic account of conditional interpretation offered here explains how attributions of specific consequence contents to conditionals depend on particular epistemic contexts without therefore becoming fully subjective. But the context of contingency planning makes relevant a host of other relations that should be mentioned briefly as they are responsible for some common uses of conditionals.

One relation that is absolutely central to contingency planning is that involved in conditional intentions, naturally expressed by conditionals with first-person action consequents like:

(41) If it snows tonight, we'll go to the mountains tomorrow.

Analogous relations are expressed as conditional commands, as in (42) below, or in the third person form by decision-making authorities, as exemplified by (43):

(42) If it snows tonight, wear your coat!

(43) If it snows tonight, Lindbergh and Scheffler report to headquarters at 2300 hours.

To respond cooperatively to a conditional command involves forming the corresponding conditional intention.

Conditional commands are a species of conditional speech acts, the cooperative use of which involves the formation of conditional commitments or intentions on the part of speakers or hearers. Other examples are conditional questions (expressed by (7): "Did he break anything? And if he did, does he have insurance?"), prompting addressees to form conditional commitments to produce an answer to the question provided by the consequent; and conditional bets, such as

(44) I bet that she won't wear her coat if it is snowing.

which require a commitment to honor the bet should the antecedent be true. ${ }^{39}$

Another relation of central importance to contingency planning is that of being a fact relevant to the achievement of some possible goal. Before deciding what to do under different

\footnotetext{
${ }^{39}$ For discussion of conditional speech acts, see Edgington (1995: 287-291), Barker (1995), Bennett (2003: 124-126), Barnett (2006). For criticism of the idea that conditionals express conditional assertions and conditional commands, see Lycan (2006). Björnsson (2007) defends the idea of conditional commands, but argues against the idea that ordinary consequence conditionals express conditional assertions.
} 
contingencies, we need to know what can and cannot be done and what the potential costs involved are, and so keep track of facts that are potential means or obstacles to various actions and goals, or that affect the consequences of our actions. Such practical relevance relations are famously expressed by conditionals where the main clause indicates a means to an end made salient by the if-clause, as in (5) above ("If you are really hungry, there are some old sandwiches in the kitchen"). But they are also expressed by a host of other conditionals the consequents of which indicate something of practical relevance to a concern actualized by the antecedent possibility:

(45) If you decide to go downtown later, the bridge is closed from 9 p.m..

(46) If you decide to go downtown, there is a sale at SAKS.

(47) If you are thinking about skipping the afternoon session, John has sacked people for less.

(48) If he dies without a will, I am his son, though not from his first marriage. ${ }^{40}$

Since these conditionals convey that the consequent holds, they too imply that material implication holds. As with consequence relations, there are neighboring relations to this relevance relation that do not have that implication, such as that of being a possibility relevant to the achievement of some possible goal. However, just as with relations neighboring consequence relations, the expression of these relations require explicit qualifications:

(49) If you decide to go downtown later, the bridge is [probably/possibly/not] closed after 9 p.m..

The reason for this, again, is that such relations cannot be fitted into our cognitive map of reality without added probabilistic or modal qualifications, and so will be less easily activated than a consequent-implying relevance relation. ${ }^{41}$

Thus far, we have covered the most prominent relations of relevance for contingency planning involving thoughts about merely possible conditions: relations involved in contingency plans or conditional intentions; relations of consequences of contingencies, or

\footnotetext{
${ }^{40}$ Example (48) is from Noh $(1998,294)$.

${ }^{41}$ Relevance conditionals are often described as speech act or discourse conditionals, with antecedents specifying the circumstances under which the consequent is discourse relevant. In Björnsson (ms1), I argue that this is wrong: relevance conditionals primarily convey contents relating facts to possible concerns, contents that often embed in unasserted contexts and as objects of propositional attitudes.
} 
independence of contingencies; and relations of relevance to various consequences or dependence relations relative to possible goals. The guiding assumption has been that conditionals are assigned contents that they make immediately salient and that such salience is primarily determined by the content's relevance to purposes for which it makes sense to introduce a proposition without presenting it as true. Applying the assumption to the most prominent purpose of non-truth-presentational introduction, that of contingency planning, I have argued that we could expect if-conditionals to express just the relations that they most commonly express: relations of consequence, independence, relevance and conditional commitment. I have also explained why, given that assumption, we should not expect ifconditionals to express any of a number of neighboring relations. Furthermore, I have argued that the contents that we can expect to be expressed are contents that satisfy material implication: they either present the consequent as true or support modus ponens (at least under "normal" circumstances). I have also argued that we should expect some conditionals to resist intelligible embedding, and expect stand-off cases that illustrate epistemic context dependence. This goes a long way towards making sense of the restrictions that we see on the contents that are expressed by indicative conditionals.

To further indicate how this pragmatic approach can account for the variety of contents that are nevertheless possible, I will briefly mention three other kinds of purpose for which non-truth-presentational introduction makes sense- the expression of speaker uncertainty about speech act prerequisites, hypothetical reasoning from someone else's premises, and perspective taking.

\section{Speaker uncertainty about speech act prerequisites}

The most obvious reason to introduce a proposition without presenting it as true is probably that it is epistemically open and thus an interesting topic for contingency planning. At other times, however, uncertainty might concern prerequisites for the success or appropriateness of the speech act one wants to perform. Both speakers and hearers are highly sensitive to whether such prerequisites are satisfied. When the antecedent of a conditional expresses what could be a prerequisite for a speech act performed by the main clause, the conditional will therefore naturally be taken to express exactly this: uncertainty about whether this prerequisite for the speech act is satisfied. Such interpretations are triggered by (13) and (14), reproduced below as (50) and (51), as well as by (52): 
(50) If you know what a dundertabbe is, that is exactly what she did.

(51) If I may toot my own horn, our group made the transition months ago.

(52) If I don't see you again before then, I hope you have a happy birthday. ${ }^{42}$

It is clear enough how the if-clauses of (50), (51) and (52) would express speaker uncertainty about prerequisites for, respectively, the intelligibility, social appropriateness and appropriate timing of speech acts made by uttering the main clause. To give a general characterization of the content of prerequisite conditionals, let $R$ signify categories of speech act perfection, such as intelligibility and social appropriateness. Given this, prerequisite conditionals of the form "If P, Q" seem to express contents of the form: The speaker is unsure whether $P$, which is an $R$-prerequisite for: $Q$.

What we should note is that prerequisite conditionals do not, typically, express conditional speech acts. Whether or not the antecedent is true, the speaker of (50), (51) and (52) would have made her assertion, or expressed her birthday wishes. While prerequisite conditionals express relations to speech acts, they are thus importantly unlike conditionals with main clauses whose illocutionary force is conditional upon the antecedent. ${ }^{43}$

\section{Non-truth-presentational introduction without uncertainty}

Thus far, we have looked at two cognitive contexts triggered by non-truth-presentational introduction: contexts of contingency planning, concerned with epistemically open possibilities, and contexts of uncertainty about prerequisites for the ongoing speech act. The former is easily made salient because contingency planning is such a central cognitive task; the latter because of our sensitivity to such prerequisites in communication. Given that these prominent contexts involve uncertainty about the truth of the antecedent, it is no wonder that in many contexts where $\mathrm{P}$ is taken for granted, "if $\mathrm{P}$ " will seem infelicitous:

\footnotetext{
${ }^{42}$ Example (52) is from Siegel (2006, 180).

${ }^{43}$ It might be worth noting that some conditionals seem to express both a conditional speech act and uncertainty about prerequisites for appropriateness of the speech act (conditionally) expressed by the main clause:
}

(i) If you don't mind me asking, why didn't you respond to the allegations?

It might also be worth noting that prerequisite conditionals are unlike relevance conditionals, which do not concern speech acts at all. In many ways, then, the common practice of treating these three kinds of conditionals on a par as "speech act conditionals", "biscuit conditionals" or "relevance conditionals" glosses over fundamental semantic differences. 
(53) John is heading out soon to buy some groceries. If he is, let him know if you need something from the store.

By adding "if he is", the speaker seems to introduce an element of significant uncertainty that jars with the prior assertion. Similarly, the following would sound odd to people with a modicum of knowledge about recent history:

(54) If Bill Clinton was President in the 90s, he didn't do enough to repeal "Don't ask, don't tell!"

On the other hand, "if P" can often be used without seemingly implying doubt concerning the antecedent:

(55) If he treats you like a slave, why don't you leave him?

(56) If I'm no longer going to be arrested for possessing cannabis for my own consumption, shouldn't I be able to grow my own? ${ }^{44}$

(57) A: John called; he is leaving now.

B: Excellent! If he is leaving now, he'll be here in 45 minutes. Let's prepare the food!

Conditional (55) might naturally be uttered in a context where the addressee has just complained about her boyfriend's behavior. Had "if" indicated uncertainty, however, the utterance would have put into question what the addressee had just said, rather than raised the question of what to do about it. Similarly, (56) fits naturally in a context where the truth of the antecedent is taken for granted, being implied by a recent government announcement. Finally, the person uttering the conditional in (57) would seem to be sure enough about the truth of the antecedent to act on it without hesitation. ${ }^{45}$

The contrast between the oddness of (53) and (54) and the naturalness of (55), (56) and (57) calls for an explanation. The first part of that explanation must be an account of a cognitive context where non-truth-presentational introduction makes sense even though the antecedent is already taken for granted; the second part must be an account of why that context is unavailable when we interpret (53) and (54).

\footnotetext{
${ }^{44}$ Example (56) is from Haegeman (2003: 321).

${ }^{45}$ These are what Iatridou (1991: 58-59, e.g.) calls "factual" conditionals.
} 
Generally speaking, non-truth-presentational introduction makes sense when a proposition is meant to be the starting point or premise for further reasoning, but where there is no interest in presenting it as true. In contexts of contingency planning, the reason not to present a proposition as true is that its truth is not taken for granted. But there might be other reasons. One reason would be that one takes the antecedent to be false and hopes to show that it is by adducing evidence against it; another is to engage in reasoning on behalf of someone else with an eye to increasing consistency:

(58) A: My friend Joe, whom you haven't met, is very smart.

B: Oh yeah? If he's so smart why isn't he rich?

(59) A: This book that I'm reading is really stupid.

B: I haven't read it, but if it's so stupid you shouldn't bother with it. ${ }^{46}$

(60) Mother: Oh, you're cold. Your lips look blue with cold.

Son: If I'm cold, please let me use your shawl. ${ }^{47}$

The reason at play in (55), (56) and (57), however, seems to be a lack of independent authority concerning the truth of the antecedent: the speaker is merely repeating a proposition introduced by someone else or in a different context, taking it on their authority. This is confirmed by the fact that their antecedents are naturally explicated with reference to the authority in question, as in:

(61) If, as you say, he has treated you like a slave, why don't you leave him?

It is quite clear why these purposes for introducing a premise for further reasoning are unlikely to be operative in (53) and (54). In (53), the antecedent is not taken on some prior authority; the speaker is the authority in question. In (54), the speaker is likely to be as much of an authority on the antecedent as his audience. ${ }^{48}$ In neither case do we get any reason to

${ }^{46}$ Iatridou (1991: 59)

${ }^{47}$ Noh (1998: 278)

${ }^{48}$ There are apparent counterexamples, where speakers seem to be current authorities on the truth of the antecedent:

(i) Don't you worry about Tom; he is here now. If he is here, he feels good.

However, the antecedent of the conditional in (i) is not specifically concerned with the situation described in the nonconditional first conjunct, as revealed by the fact that the following seems less natural:

(ii) Tom is here now. If he is here now, he feels good.

One explanation for why (i) is natural and (ii) less so is that the conditional in the former is understood as expressing a habitual or ceteris paribus generalization: 
think that the speaker is engaged in a reductio of the antecedent or is arguing from the point of view of someone else.

Since antecedents can be introduced in contexts without uncertainty as premises for much the same sorts of reasoning that matter in contingency planning, we can expect these conditionals to convey relations of consequence, independence and relevance, and to be used for conditional speech acts. By contrast, we should not expect them to express speech act requirements.

\section{Perspective taking}

I will mention one final kind of cognitive context where non-truth-presentational introduction makes sense: contexts where understanding the consequent requires taking some (typically non-actual) perspective. ${ }^{49}$ If the antecedent can be seen as indicating such a perspective, this relation to the consequent is likely to be highly salient. The relation would matter greatly for interpretation, and interpretation is highly sensitive to various kinds of perspective. We have already seen conditionals that invoke perspectives, in (9), (10), (11) and (12), reproduced her as (62), (63), (64) and (65):

(62) If we are only talking about taste, you should order the fried mozzarella sticks.

(iii) Whenever Tom is here (and there are no contravening circumstances), he feels good.

Such generalizations have the truth-conditions of REG, i.e. $(\mathrm{x})((\mathrm{Ax} \wedge \mathrm{Cx}) \supset \mathrm{Bx}) \wedge \mathrm{Cs}$, minus the second conjunct. However, when expressed in contexts where their applicability to the present case is presupposed, such expressions pragmatically imply that Cs holds, thus in effect mimicking the content of a regular particular consequence conditional. When "now" is added to the antecedent in (ii), the generalized interpretation is blocked. Conditionals are easily interpreted as generalizations for much the same reason as they are interpreted as expressing consequence relations: our regularity concepts form a core part of our cognition. In the case of generalized conditionals, the antecedent introduces a gappy proposition-one that is only true or false relative to a situation-without presenting it as true.

Another sort of counterexample involves conjunctions:

(iv) Tom is here now, and if he is here now, he feels good.

This is a little bit odd, but not nearly as odd as (ii) or (53). The reason is simply that "and" can indicate exactly that what has just been said should be understood as a premise for what is coming.

${ }^{49}$ Depending on how we understand perspective taking, this is a wide category containing conditionals expressing very different relations between a perspective introduced by the antecedent and the content expressed by the main clause. Apart from the diversity illustrated by (62) through (68), for example, premise conditionals could arguably fit into this category. However, since the relations made salient by premise conditionals coincide with conditionals for contingency planning, my concern is with a narrower class. 
(63) If you believe Gottfried, everything is fine and dandy.

(64) If you look to your right, the book is on the top shelf.

(65) If you are Lance Armstrong, what do you do next to improve?

Conditionals of this sort have a distinctively unconditional flavor: there is no sense that the consequent follows from the antecedent. (62) indicates that ordering the fried Mozzarella sticks would offer the best taste experiences, but does not suggest that this depends on what the interlocutors are talking about. ${ }^{50}$ (63) conveys that everything is fine and dandy as Gottfried sees it, but does not suggest that this depends on whether one believes Gottfried. (64) says that the book is on the top shelf (the one the addressee can see to the right), but does not suggest that this depends on whether the addressee actually looks there or not. (65) asks for a description of what Lance Armstrong is going to do next to improve (to be given in the generic "you" form: "you train harder and smarter, eat better..."), but does not suggest that this answer depends on any possibility presented in the antecedent.

In other conditionals, however, the antecedent both helps to determine the content of the consequent and presents the antecedent as something from which the consequent follows. We have already seen this phenomenon in (39), reproduced here as (66), where a conditional is embedded in the consequent of another conditional:

(66) If a Republican won the election, then if it wasn't Reagan who won, it was Anderson.

Here the antecedent indicates what consequence relation is expressed by the consequent, but is also presented as something from which the consequent follows. Other examples might be provided by advice modals:

(67) All this shooting is just stupid. If the crook wants to escape, he should kill the guard silently, with a knife.

(68) If you want to go to Harlem, you should take the A train.

Reference to what the agent wants - escape, to go to Harlem-suggests that "should" relates the action to the standard of best increasing the agent's chances of doing just that (without

\footnotetext{
${ }^{50}$ The meaning of "X should Y" is famously context dependent, meaning roughly that X's Y-ing would satisfy some relevant standards, standards that are determined by the context of utterance. See Kratzer (1977). For recent discussion, see Kolodny and MacFarlane (ms), Björnsson and Finlay (2010), Dowell (ms).
} 
unduly undermining his other interests), in which case the truth of the consequent might be independent of the antecedent: whether the crook wants to escape or not, the best way to escape might be to kill the guard silently with a knife. Alternatively, reference to what the agent wants might suggest that "should" relates the action to a standard of best satisfying the agent's preferences and interests, period. In that case, the consequent is likely to be understood as following from the antecedent: it serves your interests best to take the A train if you want to go to Harlem, otherwise not. ${ }^{51}$

Conditionals whose antecedents determine the content of the consequents are likely to provide prima facie counterexamples to modus ponens, since modus ponens involves the detachment of the consequent from the antecedent, which might then be given a different content. Take the conditional in (67), which might seem true enough in the context of watching an action movie:

(69) If the crook wants to escape, he should kill the guard silently, with a knife.

The crook wants to escape.

Hence, the crook should kill the guard silently, with a knife.

One might well find the first two premises plausible but want to reject the conclusion; the crook should not kill anyone, but instead take the opportunity to give up his miserable life in crime. $^{52}$

\section{The generation of material implication}

Most theorists concerned with conditionals have argued or assumed that the semantics of conditionals should guarantee the validity of modus ponens and modus tollens. Some have defended the material implication analysis of declarative indicatives, since it attributes the weakest truth-conditions that offer such a guarantee. Others have responded to the paradoxes of material implication by supplementing the truth-functional analysis with conventionally

\footnotetext{
${ }^{51}$ For discussion of advice modals, see von Fintel and Iatridou (2005). On Kratzer's view, unlike the present account, ifclauses do the same restrictive or perspective fixing job in all their interactions with main clauses.

${ }^{52}$ For recent discussion of interactions between "if" and "ought”, see Kolodny and MacFarlane (2010) and Finlay (2010). The apparent counterexamples to modus ponens are not limited to conditionals with conditionals or modals in the consequent, but also occur with some other perspective taking conditionals, such as (63): (i) If you believe Gottfried, everything is fine and dandy. (ii) You believe Gottfried. (iii) Hence, everything is fine and dandy. The two premises might be true while the consequent false: what follows is only that one (or "you") believes that everything is fine and dandy.
} 
given epistemic requirements, ${ }^{53}$ by suggesting stronger truth-conditions, ${ }^{54}$ or by abandoning the idea of providing a truth-conditional analysis, opting instead for a characterization of the speech act performed when uttering a conditional, ${ }^{55}$ or for a characterization of the state of mind expressed by conditionals. ${ }^{56}$

What we have seen here is how if-clauses' conventional function of introducing a proposition without presenting it as true might be sufficient to explain what is right about the requirement that conditionals satisfy material implication (while allowing for the sort of exceptions briefly discussed in section 4). We have seen why, among various kinds of neighboring relations, the consequence relation would be most easily accessible as we interpret conditionals, and we have seen why relevance conditionals present their consequents as true. But we can generalize these arguments and provide reason to think that the explanations extend to all if-conditionals: If, on the one hand, the conditional expresses some relation of dependence between antecedent and consequent, it will be a consequence conditional, supporting modus ponens (barring exception cases). To make salient probabilistically, modally weakened or exclusionary relations, we need explicit probabilistic, modal or negative markers, as the corresponding cognitive representations of the content are more complex. If, on the other hand, the conditional does not express a dependence relation, it will present the consequent as true. Again, presenting the consequent as merely probable or possible or as simply false requires explicit markers, as the corresponding cognitive representations are more complex.

\section{Concluding remarks}

I have hypothesized that the interpretation of conditionals is constrained by the assumption that the relation between antecedent and consequent is relevant to the purpose of non-truthpresentational introduction of the if-clause. This constraint, I have argued, can explain prominent features of the semantics of indicative conditionals. If correct, this gives us reason to think that non-truth-presentational introduction exhausts the semantic contribution of ifclauses, and that a form of relational contextualism is correct: conditionals have no truth-

\footnotetext{
${ }^{53}$ Jackson (1987)

${ }^{54}$ Stalnaker (1981), Nolan (2003)

55 Barnett (2006), Edgington (1995)

${ }^{56}$ Adams (1975), Edgington (1995), Bennett (2003)
} 
evaluable or intuitively complete content absent some contextually determined salient enough relation between antecedent and consequent.

Obviously, much work remains to be done, on many fronts. The account offered here needs to be extended to counterfactual conditionals. It needs to be integrated in a comprehensive theory about the syntax of conditionals and its interaction with semantics. More needs to be said about how conditionals interact with other expressions, in particular modal and probabilistic expressions. Things need to be said about how regularity concepts figure in reasoning and interact with probabilistic thinking. Popular criticism directed at contextualist theories of conditionals must be answered. And it needs to be shown that other theories of conditionals run into problems that are better handled by relational contextualism.

Some of this work has been done or is under way. ${ }^{57}$ But the arguments in this essay should be enough to show that relational contextualism is worth further examination. It offers a unified explanation of a wide variety of contents expressed by conditionals, without assimilating contents that are intuitively quite disparate and without divorcing the analysis of conditionals from the content that we intuitively take them to express. Moreover, it builds this explanation on non-truth-presentational introduction, an assumption about the conventional contribution of if-clauses that holds true on any plausible theory of conditionals. Even if it should fall short of explaining everything there is to explain about conditionals, it provides a minimal base on which further assumptions can be added-if needed. ${ }^{58}$

\footnotetext{
${ }^{57}$ Björnsson (2007, 2008, ms1, ms2), Björnsson and Gregoromichelaki (forthcoming)

${ }^{58}$ Early versions and parts of this essay have been presented at the philosophy departments at Oxford, Stockholm, Lund, Uppsala, and Gothenburg Universities, at CSU Northridge, at ECAP5, Lisbon, UICMII, Brussels, and at the CEU summer school on conditionals in Budapest in 2009; I thank the audiences at all those places for valuable comments. A special thanks goes to Ken Turner for encouraging me to finally ready a portion of my sprawling manuscripts for print, to Josep Macia for pushing me to provide better answers to the question of why a contextualist account would not overgenerate contents (I realize that question has not been fully answered yet), and to Brian Leahy and Eleni Gregoromichelaki for their comments on the penultimate draft and their willingness to discuss some of the ideas finally coming together here at various points. Funding from Åke Wibergs Stiftelse and Magnus Bergvalls Stiftelse made it possible to do some of the work on this essay in a stimulating intellectual esnvironment in London.
} 


\section{Bibliography}

Adams, E. W. 1975. The Logic of Conditionals, Dordrecht: Reidel

Allott, N. \& Uchida, H. 2009. Natural language indicative conditionals are classical. UCL Working Papers in Linguistics, 21, 1-17.

Barker, S. J. 1995. Towards a Pragmatic Theory of 'If'. Philosophical Studies 79:185-211.

Barnett, D. 2006 Zif is If. Mind 115: 519-65.

Bennett, J. 2003. A Philosophical Guide to Conditionals. Oxford U. P.

Björnsson, G. 2007. Comments on Lycan's 'Conditional-Assertion Theories of Conditionals', Philosophical Communications, Web $\quad$ Series, 43 URL http://www.phil.gu.se/gunnar/Lycan\%20Commentary.pdf

Björnsson, G, 2008. Strawson on 'if' and つ. South African Journal of Philosophy 27: 24-35.

Björnsson, G. ms1. Relevance Conditionals are Not Speech-Act Conditionals. Working paper.

Björnsson, G. ms2. In Defence of a Contextualist Theory of Conditionals. Working paper.

Björnsson, G. and E. Gregoromichelaki. Forthcoming. A Contextualist Account of the Syntax and Semantics of Conditionals. Forthcoming in Grammar and Context: A Festschrift for Ruth Kempson

Björnsson, G. and S. Finlay. 2010. Defending metaethical contextualism. Ethics 121:7-36.

Davis, W. A. 1983. Weak and Strong Conditionals. Pacific Philosophical Quarterly. 64: 57-71.

Dowell, J. ms. A Flexible Contextualist Account of 'Ought'. Manuscript.

Edgington, D. 1995. On Conditionals. Mind, 104: 235-329.

Edgington, D. 2008. Counterfactuals. Proceedings of the Aristotelian Society 108:1-21.

Finlay, S. 2010. What 'ought' probably means, and why you can't detach it'. Synthese 177:67-89.

von Fintel, K. and S. Iatridou 2005. What to Do If You Want to Go to Harlem: Anankastic Conditionals and Related Matters. Manuscript. URL: http://mit.edu/fintel/www/harlem-rutgers.pdf

Gibbard, A. 1981. Two recent Theories of Conditionals. In Harper, W. L., R. Stalnaker and G. Pearce, eds., Ifs, pp. 211-47. Dordrecht: Reidel.

Goodman, N. 1947. The Problem of Counterfactual Conditionals. Journal of Philosophy 44:113-128.

Grice, H. P. 1975. Logic and Conversation. In Cole, P. and J. Morgan, eds., Syntax and Semantics 3: Speech Acts, pp. 41-58. New York: Academic Press.

Haegeman, L. 2003. Conditional clauses: External and internal syntax. Mind and Language 18: $317-$ 339. doi:10.1111/1468-0017.00230.

Iatridou, S. 1991. Topics in conditionals. Ph.D. thesis, MIT.

Jackson, F. 1987. Conditionals. Blackwell.

Kolodny, N. and J. MacFarlane. ms. Ought: Between Subjective and Objective. Manuscript

Kolodny, N. and J. MacFarlane. 2010. Ifs and oughts. Journal of Philosophy 107: 115-143. 
Kratzer, A. 1977. What must and can must and can mean. Linguistics and Philosophy 1: 337-355. doi:10.1007/BF00353453.

Lycan, W. G. 2001. Real Conditionals. Oxford U. P.

Lycan, W. G. 2006. Conditional-Assertion Theories of Conditionals. In Thompson, J. and Byrne, A., eds., Content and Modality: Themes from the Philosophy of Robert Stalnaker, pp. 148-164. New York: Oxford University Press. URL http://www.unc.edu/ ujanel/CondAssnThs.htm.

McGee, V. 1985. A Counterexample to Modus Ponens. Journal of Philosophy 82: 462-71.

Mele, A. 2009. Effective Intentions: The Power of Conscious Will. Oxford U. P.

Millikan, R. G. 1984. Language, Thought, and Other Biological Categories: New Foundations for Realism. Cambridge, MA: MIT Press.

Millikan, R. G. 2000. On Clear and Confused Ideas: An Essay about Substance Concepts. New York: Cambridge U. P.

Millikan, R. G. 2005. Language: A Biological Model. Oxford: Clarendon Press.

Morton, A. 2004. Against the Ramsey Test. Analysis 64: 294-9.

Noh, E.-J. 1998. A relevance-theoretic account of metarepresentative uses in conditionals. In Rouchota, V. and A. H. Jucker, eds., Current Issues in Relevance Theory, pp. 271-304 Amsterdam: John Benjamins

Nolan, D. 2003. Defending a Possible-Worlds Account of Indicative Conditionals. Philosophical Studies 116: 215-69.

Siegel, M. E.A. 2006. Biscuit conditionals: Quantification over potential literal acts. Linguistics and Philosophy 29: 167-203. doi:10.1007/s10988-006-0003-2.

Smith, N. and A. Smith. 1988. A Relevance-theoretic Account of Conditionals. In Larry M. Hyman; Charles N. Li, eds., Language, Speech and Mind: Essays in Honour of Victoria A. Fromkin, pp. 322-352. London: Routledge.

Stalnaker, R. 1981. Indicative Conditionals. In W. L. Harper, R. Stalnaker and G. Pearce, eds. Ifs, pp. 193-210. Dordrecht: Reidel

Weatherson, B. 2009. Conditionals and indexical relativism. Synthese 166: 333-57.

Williams, B. 2006 Ethics and The Limits of Philosophy, Routledge. 